\title{
Pamela Harris: The Mathematical Rise and Social Contribution of a Dreamer
}

\author{
Ricardo Cortez and Federico Ardila
}

Originally introduced in 2001, the DREAM Act is legislation intended to provide a pathway toward legal status for eligible undocumented youth, known as Dreamers. In 2012, as this pathway was debated, the Obama administration announced the Deferred Action for Children Arrivals (DACA) policy, which deferred deportation for young people who arrived in the United States as children. However, in September of 2017, the United States Department of Homeland Security announced that no new DACA applications would be accepted. Meanwhile, despite bipartisan support for its various iterations, the DREAM Act has not become law.

One of these young Dreamers is Pamela E. Harris, who emigrated from Mexico to the USA with her family when she was twelve years old. Her parents moved away from their families and friends, and gave up their language and their support system in an attempt to provide better opportunities for their children, particularly in education. This sacrifice became a driving force for Pamela to excel in her studies and make her parents proud of her accomplishments. Living under challenging financial strain at times, she became the first member of her family to graduate from high school. It is difficult to overstate the significance of this milestone for her and for her family; Pamela did not feel she had any more to prove. But she always liked mathematics, she was good at it, and she wanted to go further. Even as a young girl she would ponder about scale, the size of the universe, and infinity. As an adult, her determination to keep learning and her desire to serve her community motivated her to push forward.

Ricardo Cortez is the Pendergraft William Larkin Duren Professor of Mathematics at Tulane University. His email address is rcortez@tulane.edu.

Federico Ardila is professor of Mathematics at San Francisco State University, and profesor adjunto at Universidad de Los Andes. His email address is federico@sfsu.edu.

For permission to reprint this article, please contact: reprint-permission@ams .org.

DOI: http://dx.doi.org/10.1090/noti1723

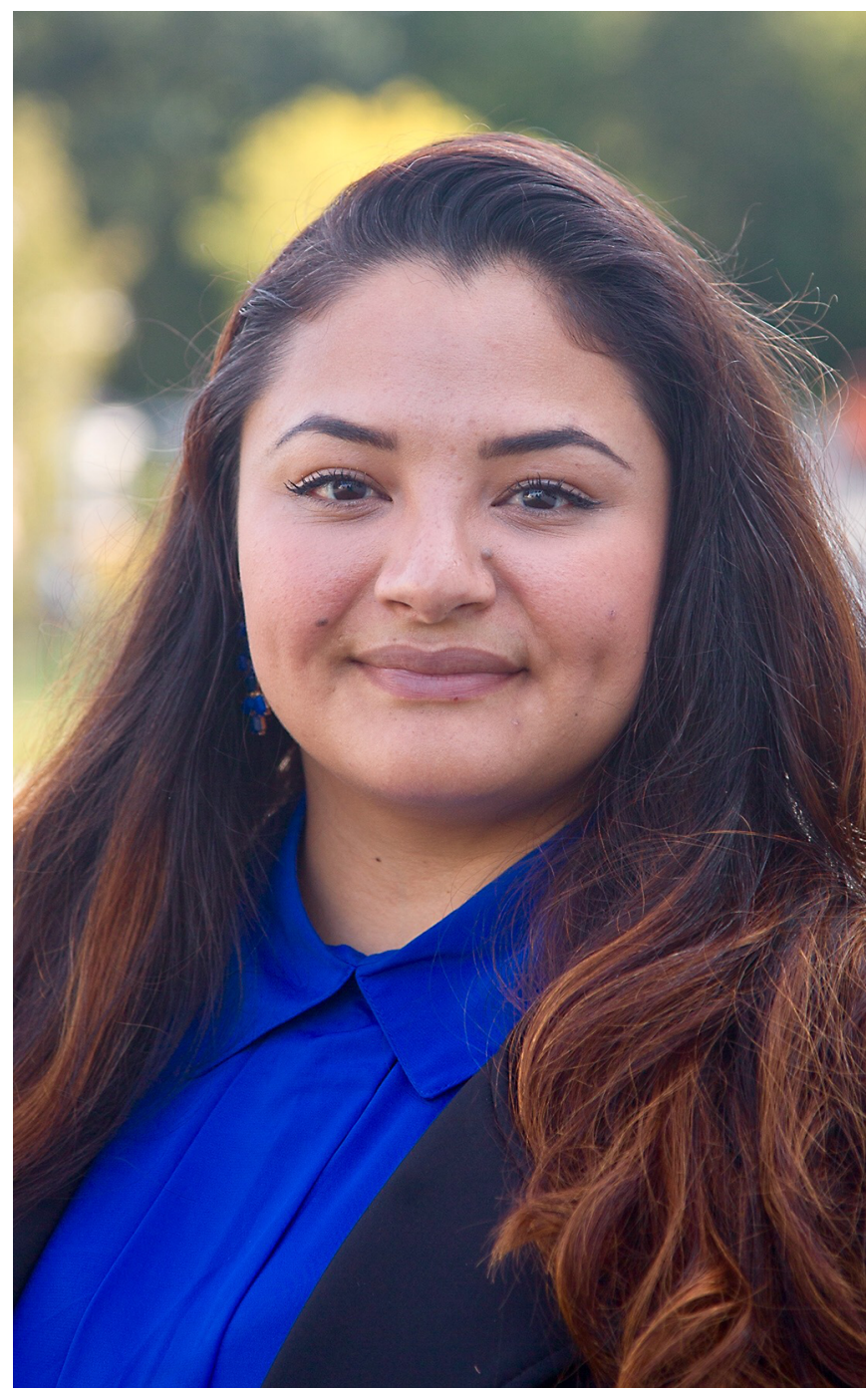

Pamela Harris emigrated from Mexico to the United States with her family as a young girl. 
Being undocumented is not something one advertises freely. So, how does a young person in that situation, facing discrimination and numerous structural obstacles, manage to go to college? At the time, there were few educational opportunities available to Pamela. Financial aid applications required documentation that she did not have access to, and it was impossible for her to attend college without financial support. It took some creative form-filling, and hoping that nobody found the inconsistencies in the paperwork, for Pamela to be on her way to the Milwaukee Area Technical College, where she earned two associate degrees. Along the way, her connection to mathematics was reinforced. Her personal life was also blossoming: She married her husband Jamual and started a family of her own.

Subsequently, as a US Resident, she attended Marquette University as an undergraduate and received her master's and PhD degrees from the University of Wisconsin at Milwaukee, while raising her young daughter Akira. Pamela went on to be both a teaching postdoc and a Davies Research Postdoctoral Fellow at the United States Military Academy. Since 2016, she has been an assistant professor of mathematics at Williams College.

Pamela is a prolific researcher with broad interests. Since 2016 she has published or submitted thirty research papers, and received grants from the National Science Foundation and the Center for Undergraduate Research in Mathematics. She constantly seeks out new collaborations, connects different points of view, and builds bridges across disciplines. She has brought together a vibrant community of investigators working together on important problems.

Pamela Harris's research is in algebraic combinatorics, particularly in connection with the representation theory of Lie algebras. For example, in her PhD thesis and subsequent papers, she offered a new perspective on Kostant's formula for the multiplicity of a weight in an irreducible representation of a semisimple Lie algebra. This formula is an impractically large sum over the elements of the corresponding Weyl group. For the classical Lie algebras, Pamela [3] and her collaborators [4] determined that the vast majority of the terms in this sum vanish, and they enumerated the contributing terms; these are rather unexpected results on a central object in mathematics.

Another important contribution is her work [2] on peak polynomials, which enumerate permutations with a given set of peaks. These polynomials were conjectured in [1] to have positive coefficients when written in a binomial basis. Pamela and her collaborators proved the conjecture by devising a clever new way of computing peak polynomials, which transparently implies their positivity.

In addition to her outstanding research trajectory, Pamela has an unwavering commitment to her communities. She has worked with more than 25 undergraduate students on research projects and is looking forward to being the research leader for the MSRI Undergraduate Program in 2019. She has led efforts to secure funding for mathematics sessions and for student travel scholarships for the Society for the Advancement of Chicanos/Hispanics and
Native Americans in Science (SACNAS) conference. She has organized multiple speaker series and conferences with a focus on underrepresented minorities, and co-founded Tathisms.org, a website and calendar that highlights the research and mentoring contributions of Latinxs in mathematics. By excelling as a researcher, teacher, and advocate for positive change in the mathematical community, Pamela Harris serves as an inspiring example to the next generation of young mathematicians. [5]

Pamela Harris's extraordinary research program and service work are not only deep and meaningful, they also exemplify the talent, drive, and leadership of Dreamers in the United States and their tremendously important professional and social contributions.

\section{References}

[1] Billey, S., Burdzy, K., \& SAgan, B. E., Permutations with given peak set. Journal of Integer Sequences, 16(6) (2013). MR3083179

[2] DiAZ-LOPEZ, A., HARRis, P. E., InSKo, E., \& OMAR, M., A proof of the peak polynomial positivity conjecture. J. Combinatorial Theory, Series A 149 (2017), 21-29. MR3620729

[3] HARRIS, P. E., On the adjoint representation of $\mathfrak{g l}_{n}$ and the Fibonacci numbers C. R. Math. Acad. Sci. Paris 349 (2011) pp. 935-937. MR2838238

[4] HARRIS, P. E., INSKO, E., \& Williams, L. K., The adjoint representation of a classical Lie algebra and the support of Kostant's weight multiplicity formula. J. Combinatorics 7(1) (2016), 75-116. MR2838238

[5] Strength in Numbers. Williams College Web site. Available at: https://www.wi 11iams.edu/feature-stories/strengthin-numbers. Accessed June 25, 2018.

Photo Credit

Photo of Pamela Harris courtesy of Cesar E. Silva. 